\title{
De la escuela al hogar; la formación de la enfermera visitadora
}

\section{From school to home; the visiting-nurse}

Dra. Claudia Agostoni

La Escuela de Salubridad, inaugurada el 17 de febrero de 1922 y ubicada en la Calle del Chopo 16 de la Ciudad de México, abrió sus puertas para dotar de una formación especializada en materia de medicina preventiva a los médicos titulados. Entre 1922 y 1925, únicamente los profesionales de la salud podían optar por el diploma de oficial de salubridad, o bien, por el diploma de estudios superiores de higiene y salubridad pública. ${ }^{2-3}$ Sin embargo, y frente a la urgencia de que el país contara con un mayor número de especialistas en materia de medicina preventiva, esa restricción se eliminó el 31 de marzo de 1925. A partir de ese momento, la institución abrió sus puertas al público en general y asumió la responsabilidad de preparar a un personal técnico no graduado en medicina que podría optar por los siguientes diplomas: ayudante de laboratorio (comprendiendo laboratorio químico y bacteriológico), agente de des-

\section{cकैके}

- Dra. en historia e Investigadora Titular en el Instituto de Investigaciones Históricas de la Universidad Nacional Autónoma de México (UNAM)

Correspondencia: agostoni@servidor.unam.mx

* El artículo que aquí se reproduce forma parte de una investigación más amplia. Véase Claudia Agostoni: "Las mensajeras de la salud. Enfermeras visitadoras en la ciudad de México durante la década de los 1920". En Estudios de Historia Moderna y Contemporánea de México. Volumen 33, enero-junio 2007, pp. 89-120. Se reproduce con autorización de la autora. infección, agente de enfermedades infecciosas, inspector de bebidas comestibles, ayudante de bebidas y comestibles, enfermera visitadora y agente sanitario. $^{2}$

De acuerdo con las autoridades de salud, sólo mediante la capacitación de un personal especializado en medicina preventiva sería posible dotar al país de un verdadero "ejercito sanitario", cuyas tareas serían de primera importancia para hacer del pueblo mexicano uno sano, vigoroso y culto. ${ }^{4}$ El beneplácito con el cual algunos periódicos celebraron la formación de ese ejército sanitario llevó a que El Universal manifestara como sumamente alentador que México estuviera en vías de crear un ejército de enfermeras visitadoras. Además, alababa las disposiciones gubernamentales que buscaban "inculcar en la mente de las madres aquellos consejos que sean indispensables para la salud de sus niños". ${ }^{5}$ 
Espinosa de los Reyes, se alejaba de la tradicional imagen de la enfermera. No se trataba de la enfermera bajo la dirección de alguna orden religiosa y cuyos conocimientos derivaban de la experiencia adquirida en el trato y el cuidado de los enfermos en el hospital. ${ }^{7-10}$ Tampoco se trataba la enfermería como un apostolado, o a la enfermera como "hermana de la caridad". Durante el transcurso de la década de 1920, en la figura de la enfermera visitadora se unió el conocimiento científico especializado a la tradición caritativa y educadora de las "damas visitadoras", presentes con relativa abundancia en diversos países europeos y del continente americano durante el transcurso del siglo XIX. ${ }^{11-13}$ Para los funcionarios del Departamento de Salubridad Pública, la formación de un cuerpo de enfermeras visitadoras era primordial debido a que ellas efectuarían visitas a los hogares para enseñar los principios teóricos y prácticos de los cuidados que requería recibir la niñez y la mujer embarazada; darían instrucciones precisas relativas al manejo científico e higiénico del ámbito doméstico y divulgarían consejos referentes a la higiene de la alimentación y de la higiene corporal. ${ }^{14}$ Si la crianza de los niños era una "ciencia", de acuerdo con la opinión de diversos médicos diplomados, "sin guía técnica alguna, sirviéndose de los consejos de amigas, comadres, vecinas y otras personas igualmente incapacitadas", muchas mujeres provocaban la muerte de sus propios hijos. ${ }^{15}$ Precisamente para guiar, supervisar y erradicar la supuesta "ignorancia materna" y por "razones de humanidad que han promovido la mayoría de los países civilizados", 15
Entre 1925 y 1929, las

mujeres que optaron

por ingresar al curso de enfermera visitadora en

la Escuela de Salubridad no requerían contar con una educación médica formal, y tampoco con el título de enfermera.

se alentó e impulsó la capacitación de las enfermeras visitadoras.

Entre 1925 y 1929, las mujeres que optaron por ingresar al curso de enfermera visitadora en la Escuela de Salubridad no requerían contar con una educación médica formal, y tampoco con el título de enfermera. Lo que sí era necesario era que aprobaran un año de cursos que incluía, entre otras, las siguientes materias: nociones generales de higiene pública y personal, alimentos y vitaminas para mujeres embarazadas y para los infantes, métodos para conservar la leche limpia y leche especial para niños, el ejercicio desde el punto de vista higiénico, higiene de la habitación, problemas relacionados con el alcoholismo y nociones generales de salud sexual y de enfermedades transmisibles. ${ }^{16}$ A partir de 1926, también se les exigió conocer lo establecido en el Código Sanitario de los Estados Unidos Mexicanos expedido ese mismo año y que su- plantó a su antecesor porfiriano, al Código Sanitario de 1903.

De acuerdo con un informe de la Escuela de Salubridad, durante el año escolar comprendido entre julio de 1926 y junio de 192731 mujeres obtuvieron el diploma de enfermera visitadora. Esta última cifra se repitió con pequeñas variaciones en 1929 y 1930. Sin embargo, un informe de 1927 asentó que el número de mujeres que asistió a alguno de los cursos fue de 2095.** Lo anterior apunta hacia la extraordinaria recepción que tuvo la apertura de una novedosa forma para ingresar al mundo del trabajo asalariado, un trabajo que no contradecía o ponía en entredicho algunas de las ideas entonces predominantes en torno del deber ser de la mujer: respeto a las jerarquías, obediencia, sumisión, así como amor a la patria y respeto hacía las instituciones.

La enfermera visitadora, siempre dando fiel seguimiento a las directrices establecidas por los centros de higiene infantil, requería divulgar en los hogares los preceptos de la higiene prenatal y posnatal, los de higiene colectiva e individual "con el fin de evitar la influencia nociva del medio sobre la colectividad, y muy especialmente sobre el organismo infantil". ${ }^{14}$ Es decir, requerían informar a la población como criar a los niños de "modo racional"17 al destacar los peligros de la enfermedades infec-

\footnotetext{
** Me parece importante subrayar que la información relativa al número de mujeres que obtuvo el diploma de enfermera visitadora es sumamente desigual y en ocasiones poco clara. Por ejemplo, de acuerdo con el Servicio de Higiene Infantil y la Escuela de Salubridad, durante el ciclo escolar 1926-1927, 31 mujeres obtuvieron el diploma; no encontré información relativa a 1928; en 1929 fueron 30 las enfermeras visitadoras aprobadas, y en 1930 nueve alumnas aprobaron los cursos. ${ }^{16}$
} 
tocontagiosas, de la automedicación y del charlatanismo, así como al subrayar la importancia que tenía la alimentación y el aseo de la mujer durante el embarazo y la higiene y alimentación artificial o materna de los infantes.

\section{REFERENCIAS BIBLIOGRÁFICAS.}

1 Agostoni C. Las mensajeras de la salud enfermeras visitadoras en la Ciudad de México durante la década de los 1920. Estudios de Historia Moderna y Contemporánea de México 2007; 33:90-120.

2 Valdespino JL, Sepúlveda J. (compiladores). Crónica de la Escuela de Salud Pública de México de 1922 a 2001. Libro conmemorativo. México: Escuela de Salud Pública de México/ Instituto Nacional de Salud Pública; 2002, p. 36.

3 Pruneda A. Discurso de inauguración de la Escuela de Salubridad. Boletín del Departamento de Salubridad Pública 1922; 2 (1-6): 133-136.

4 Briones A. Breves consideraciones acerca de la higiene en cortas poblaciones y sus relaciones con el Consejo de Salubridad. Memoria del VII Congreso Médico Nacional en Saltillo, Coahuila del 24 al 30 de septiembre de 1922, México: Talleres Gráficos de la Nación; 1923, v. 2, p. 149.

5 La tarea de la mujer evitando la mortalidad. El ejército de enfermeras visitadoras. Los sentimientos de piedad, El universal, 1927 septiembre 6; p. 6.

6 Espinosa de los Reyes I. La mortalidad de la primera infancia en México: sus causas y remedios. Gaceta Médica de México 1923; tLV (apéndice al No. 3), p. 852.

7 Villa-Guerrero G. Las enfermeras. Otro rostro de la Revolución. Solo historia. México, Instituto Nacional de Estudios Históricos de las Revoluciones de México 2000: 8: 47-52.

8 Rocha-Islas ME. Leonor Villegas de Magnón. La Organización de la Cruz Blanca Nacional, 1914. Dimensión Antropológica 2002; 25 (año 9): 59-89.

9 García García G. El Servicio médico durante la Revolución Mexicana, México, Editores Mexicanos Unidos, 1982.

10 Darrow M. French volunteer nursing and the myth of the war experience in World War I. The American Historical Review 1996; 101(1):80-106.

11 Schell P. An honorable avocation for ladies. The work of the Mexico City Unión de Damas Católicas Mexicanas, 1912-1926. Journal of Women's History 1999; 10(4):78-103.

12 Adams C. Maternal societies in France. Private charity before the welfare State. Journal of Women's history 2005; 16(1): 87-111.
13 Jonathan Barry y Colin Jones (editors), Medicine and charity before the Welfare State, London, Routledge, 1991.

14 Departamento de Salubridad Pública. Servicio de Higiene Infantil. Boletín del Departamento de Salubridad 1929; 3:3. Memoria de los trabajos realizados por el Departamento de Salubridad Pública, 1925-1928, México, Ediciones del Departamento de Salubridad Pública; 1928, t. 1, p. 163.

15 Departamento de Salubridad Pública. El servicio de enfermeras visitadoras voluntarias. Boletín del Departamento de Salubridad Pública 1927; 2: 9-18.

16 Departamento de Salubridad Pública. Informe anual de las labores desarrolladas en la Escuela de Salubridad anexa al Departamento del mismo nombre, desde el 1 de julio de 1926 hasta el 30 de junio de 1927. Archivo Histórico de la Secretaria de Salud (en adelante, AHSS) Fondo Salubridad Pública, Sección Establecimientos Dependientes, Serie Escuela de Salubridad, caja 1, exp. 11.

17 Departamento de Salubridad Pública. Memoria de la creación del Servicio de Higiene Infantil. AHSS, Fondo Salubridad Pública 1927; v. 2, p. 18. 